\title{
ANÁLISES DE LIVROS
}

MOTOR DEVELOPMENT IN CHILDREN. E. FEDRIZZI, G. AVANZINI, P. CRENNA, editores. Mariani Foundation Neurology Series: 2 . Um volume (17x24,5 cm) encadernado, com 185 páginas (ISBN 086196448 9). London, 1994: John Libbey \& Co. Ltd. (13 Smiths Yard, Summerley Street, London SW18 4HR, England, UK).

Este livro é a compilação de palestras ministradas em Curso de Pós-Graduação da Fundação Pierfranco e Luisa Mariani, realizado em Milão, de 10 a 12 de março de 1993. Como tal, é compreensível que todos os tópicos sobre o desenvolvimento motor da criança não puderam ser abordados de forma completa, sendo privilegiados aqueles nos quais avanços científicos tenham sido recentemente adquiridos.

Após um primeiro capítulo bastante sucinto sobre a ontogênese das estruturas telencefálicas envolvidas no controle motor, seguem-se sete capítulos nos quais são abordados aspectos relacionados ao desenvolvimento das habilidades motoras finas, postural e de locomoção, nos dois primeiros anos de vida em crianças normais. Entremeados, há dois capitulos em que se analisam dados obtidos em crianças com paralisia cerebral.

Na segunda parte do livro, composta por outros seis capitulos, os temas enfocados são o desenvolvimento do sistema visual e da motricidade ocular extrínseca. Un deles é dedicado aos modelos neurobiológicos da visāo em lactentes, enquanto os demais tratam das bases neurológicas dos movimentos sacádicos e de seguimento, aspectos relacionados ao desenvolvimento, observados no primeiro ano de vida, e avaliação do nistagmo optocinético como ferramenta clínica de avaliação visual. Alguns achados encontrados em crianças com déficit visual, com a forma diplégica da paralisia cerebral, são correlacionados às lesōes encontradas mediante estudos de imagem por ressonância magnética.

Trata-se de publicação destinada ao neuropediatra interessado em obter conhecimentos atuais acerca das bases neurobiológicas do desenvolvimento em crianças nos dois primeiros anos de vida. $\dot{\mathrm{E}}$, portanto, um livro cujo interesse maior está voltado a um público limitado. Entretanto, trata-se de publicação de importância capital para o pesquisador que estuda a neurologia do desenvolvimento.

JOSÉ LUIZ DIAS GHERPELLI

VEINTE CINCO AÑOS DE NEUROLOGIA EN EL ECUADOR [TWENTY-FIVE YEARS OF NEUROLOGY IN ECUADOR](1969-1994). MARCELO E. CRUZ. Um volume (14,5x20,5 $\mathrm{cm}$ ) em brochura, com 332 páginas (ISBN 99 78-82-537-1. Quito, 1994: Academia Ecuatoriana de Neurociencias (Ramérez Dávalos 136, Quito, Ecuador).

Este texto em castelhano e em inglês apresenta a visão do autor sobre o desenvimento da Neurologia e das especialidades afins em seus país, o Equador. A evolução dos conhecimentos é revista desde seus primórdios até o presente, em cujos últimos 25 anos se fez sentir de perto a atuação firme e a liderança de Marcelo Cruz. Suas contribuições e aquelas de sua escola são apresentadas nas duas partes que compõem este compêndio.

Na primeira parte, após introdução e listagem das principais contribuições registradas internacionalmente entre 1969 e 1994, são reunidas as contribuiçōes ligadas a neuroepidemiologia, deficiencia de iodo, teníase/ cisticercose, história da neurologia.

A segunda parte abrange os registros relacionados ao "Projeto San Pablo", estudo multidisciplinar recentemente conduzido sob a égide de Marcelo Cruz. Trata-se de programa comunitário de investigaçãointervenção desenvolvido no povoado de San Pablo del Lago, na Província de ímbabura, situada no norte do Equador. Esse projeto se desenvolveu sob os auspícios do Centro Internacional de Investigaçōes para o Desenvolvimento, do Canadá, com a colaboração do Centro de Controle e Prevenção de Doenças, de Atlanta, EUA. Recebeu ele o apoio de diversas entidades internacionais e do Equador, graças ao qual foi possível levar a cabo tão importante tarefa. Desse projeto, são destacadas neste compêndio os registros ligados a: situaçāo da saúde na Província de Imbabura: parasitoses e malnutrição em crianças de idade escolar: efeitos sobre a função 
cognitiva e o EEG; estudo comparativo a nível comunitário entre praziquantel e albendazol para controle de helmintíases intestinais; educação para a saúde: estratégia para a prevenção de doenças parasitárias em uma área rural; prevalência da neurocisticercose em uma comunidade andina.

Trata-se o livro, portanto, de cuidadosa recompilação de caráter expositivo e crítico, do principal da experiência vivida pelo Autor $\mathrm{e}$ por seus colaboradores - a qual se mostra de grande valia para os que se dedicam ao estudo da Neurologia Tropical e Geografica.

ANTONIO SPINA-FRANCA

CEFALÉIAS E ALGIAS DA FACE (DIAGNÓSTICO E TRATAMENTO). Segunda Edição. GABRIEL GITAHY DE ALENCASTRO. Um volume $(14 \times 21 \mathrm{~cm})$ encadernado, com 102 páginas. Rio de Janeiro, 1994: EPUC, Editora de Publicações Científicas Ltda. (Rua Major Suckow 30, 20911-160 Rio de Janeiro RJ, Brasil).

Baseando-se na própria experiência clínica, Gitahy de Alencastro oferece a visāo prática do cuidar da cefaléia e das algias da face. Como em sua primeira edição, este opúsculo é voltado ao exercício da missão hipocrática de cuidar da dor.

A matéria do livro é distribuida em doze capítulos, dez dos quais voltados às cefaléias. Após analisar aspectos gerais das cefaléias no primeiro capítulo, sucessivamente o Autor trata de aspectos principais do diagnóstico das condutas atualmente adotạdas no tratamento de cefaléias psicogênicas, enxaqueca, cefaléia "cluster", hemicrância crônica paroxística, cefaléias dos tumores intracranianos, cefaléias da hipertensão (arterial), cefaléias dos epilépticos, cefaléias da arterite temporal. Em separado, são analisadas peculiaridades das cefaléias na infância (Capítulo XII).

A nevralgia do trigêmeo e as algias da face são estudadas no décimo capítulo, seguido do estudo da neuralgia ou síndrome paratrigeminal de Raeder.

A bibliografia reune 74 referëncias. Índice remissivo completa o volume.

No decorrer de todo o texto, é preciosa a preocupação do Autor no transmitir precisamente cada um dos seus conceitos sobre a matéria, assim como as principais condutas que recomenda. Seus conhecimentos sobre o assunto e sua experiência clínica são os guias principais com que trata cada um dos temas.

ANTONIO SPINA-FRANCA

\section{ROLE OF TIZANIDINE IN THE TREATMENT OF SPASTICITY. ROBERT $R$. YOUNG,} editor. Neurology 1994, Volume 44, Supplementum 9 (November).

Recentemente, publicamos em resumo os principais processos destinados ao tratamento clínico e neurocirúrgico em várias formas de espasticidade, provocadas principalmente pela esclerose múltipla e pelo traumatismo da medula espinhal. Nesta presente publicação, organizada e editada por Robert R. Young, do Departamento de Neurologia da Universidade da Califórnia, com a colaboração de diversos especialistas, achase delineada uma série de estudos sobre a terapêutica pela tizanididina, produto existente no mercado brasileiro, lançado pelo Laboratório Sandoz.

Inicialmente, levanta-se a indagaçāo: o tratamento da espasticidade é necessário? Na realidade, a tizanidina melhora as incapacidades e ajuda o tratamento de alguns pacientes. Ao que parece, a terapêutica dirigida aos sintomas espásticos, debilitantes, pode auxiliar os pacientes a superar a incapacidade funcional, prevenindo complicações sérias. No primeiro artigo, Coward reune as principais investigaçōes realizadas nos últimos vinte anos e que explicam a sede e o módo de ação da tizanidina. Revê as hipóteses dos investigadores para avaliar as atividades miotonolíticas, antinociceptivas e anticonvulsivas da droga, dependendentes de suas propriedades como agonista dos receptores alfa-2 noradrenérgicos. A atividade depressora sobre o sistema nervoso central, com o uso de outros agentes, toma a tizanidina um complemento valioso para o tratamento farmacológico da espasticidade. Robert $R$. Young investiga os méritos de terapêuticas farmacológicas mais novas e invasivas, relativamente à redução do desconforto do paciente e às possibilidades de restauração funcional. Delwaide $\mathrm{e}$ Pennisi analisam a tizanidina e o controle medular eletrofisiológico em pacientes com espasticidade. Fisiopatologicamente, a espasticidade resulta de várias anormalidades em circuitos neuronais da medula. Técnicas 
eletrofisiológicas não invasivas podem ser usadas para estudos em humanos para avaliar essas anormlaidades. Delwaide e Pennisi apresentam aquelas que permitem avaliar a função de algumas vias neuronais da medula espinhal. Esses autores apresentam correlações entre resultados e testes e algumas características específicas da espasticidade, assim como os efeitos satisfatórios da tizanidina quando os resultados sâo avaliados por esses testes. Robert e col. descrevem detalhes do uso do teste do pêndulo de Wartenberg, teste que permite avaliaçōes sensíveis do tono muscular através da medida do ângulo de balanceamento da perna em reposta à gravidade. Assim, torna-se possível uma avaliação detalhada da resposta da espasticidade aos agentes terapêuticos.

Na segunda parte deste Suplemento, são registrados resultados clínicos concernentes à tizanidina. Os estudos incluem uma avaliaçāo de ensaios placebo controlados, duplo-cegos, comparativamente a estudos com a tizanidina. Esses ensaios multicontrolados por placebo, no Reino Unido e nos Estados Unidos, envolviam pacientes com esclerose múltipla. Em outro ensaio, norte-americano, incluindo Canadá e Estados Unidos, foi avaliada a tizanidina em pacientes com espaticidade decorrente de lesões da medula espinhal. No estudo norteamericano, Smith e col. registram que, do ponto de vista do paciente e do médico, foram registradas diferenças nos testes de tono muscular, em relação aos pacientes que receberam placebo. No que concerne à espasticidade dependente de lesão medular, Nance e col. usaram o teste do pêndulo em combinação com outras medidas do tono musculare e demonstraram melhoras progressivas nos pacientes tratados com tizanidina. É importante assinalar que, nesses dois estudos, os benefícios da tizanidina não se acompanhavam de al terações significativas da força muscular. Lataste e col. reviram estudos duplo-cegos comparando a tizanidina com as duas drogas mais amplamente usadas atualmente, o bacoflen e o diazepan, em pacientes com espasticidade de várias origens neurológicas. Sua análise combinou os achados de mais de vinte estudos. Confirmaram a potencialidade da tizanidina como um anti-espástico. Aspectos comuns dos estudos controlados por placebos permitiram a combinação de resultados, com dados amplamente suficientes para permitir análises de grupos e subgrupos e nāo apenas em estudos individuais. Nestas análises, registradas por Wallace, a tizanidina foi encontrada como apta para reduzir os sintomas de espasticidade em pacientes com esclerose múltipla ou traumatismos medulares, sern aumentar a fraqueza muscular. No estudo britânico, o emprego da tizanidina foi acompanhado de forma prospectiva e duplo-cego em 187 pacientes com esclerose múltipla. A dose de $2 \mathrm{mg}$ era tomada oralmente por 9 semanas, precedida de uma fase de titulação durante 3 semanas. Comparado ao grupo placebo, o medicamento produziu redução significante da espasticidade muscular. Na dose eficiente, entre 24 e $36 \mathrm{mg}$, administrada diariamente, em 3 doses, a tizanidina produziu redução média de $20 \%$ do tono muscular. Aproximadamente $75 \%$ dos pacientes com todos os graus de espasticidade melhoraram de seu quadro hipertônico sem se queixar de redução da força muscular. $O$ início da melhora era referido já na primeira semana de tratamento e seu efeito se mantinha inalterado uma semana após a suspensão da terapêutica.

Os diversos relatórios são seguidos do registro das amplas discussões entre os participantes do simpósio que deu origem ao presente Suplemento. Esse simpósio foi realizado em San Francisco, California, em 16 de abril de 1994. 